\title{
CASCA DE ARROZ CARBONIZADA NA COMPOSIÇÃ̃O DE SUBSTRATOS PARA EMERGÊNCIA E PRODUÇÃO DE MUDAS DE Acacia mangium Willd.
}

Case of carbonized rice in the composition of substrates for emergency and production of changes Acacia mangium Willd

Cáscara de arroz carbonizado en substratos para la composición emergencia y plantas de producción de Acacia mangium Willd

\author{
Katiani Alves Bezerra*1, Marayane Gonçalves Sanção ${ }^{1}$, Douglas Gonçalves², Priscila \\ Bezerra de Souza ${ }^{3}$. \\ ${ }^{1}$ Curso de Engenharia Florestal, Universidade Federal do Tocantins, Gurupi, Tocantins, Brasil. \\ 2 Doutorando em Engenharia Florestal, Universidade Federal de Lavras, Lavras, Minas Gerais, Brasil. \\ ${ }^{3}$ Profa. Dra. do Curso de Engenharia Florestal, Universidade Federal do Tocantins, Gurupi, Tocantins, Brasil.
}

*Correspondência: Avenida Roraima, $n^{\circ}$ 222, entre ruas 19 e 20, Jardim Paulicéia, Gurupi, Tocantins, Brasil. CEP: 77470-000.e-mail: katiani@uft.edu.br

Artigo recebido em 05/04/2017 aprovado em 28/06/2017 publicado em 13/07/2017.

\section{RESUMO}

Objetivou-se avaliar a influência da casca de arroz carbonizada no crescimento inicial de mudas de Acacia mangium Willd. O experimento foi desenvolvido no viveiro florestal da Universidade Federal do Tocantins, campus de Gurupi-TO, conduzido em delineamento inteiramente casualizado, com cinco tratamentos T1: 0\% de Casca de Arroz Carbonizada (CAC) $+100 \%$ de Substrato comercial Bioflora ${ }^{\circledR}$, T2: $25 \%$ de CAC + 75\% Substrato comercial; T3: 50\% de CAC + 50\% Substrato comercial; T4: 75\% de CAC + 25\% Substrato comercial; T5: 100\% de CAC $+0 \%$ Substrato comercial, com 4 repetições, cada repetição com 18 sementes. Foram analisadas porcentagem de emergência (\% E), altura da parte aérea $(\mathrm{H})$, diâmetro do coleto $(\mathrm{DC})$, peso de matéria seca da parte aérea (PMSPA), peso de matéria seca das raízes (PMSR) e peso de matéria seca total (PMST). Os resultados indicaram que a utilização de casca de arroz carbonizada adicionada em diferentes proporções ao substrato comercial Bioflor ${ }^{\circledR}$ apresentou resultados significativos nos parâmetros analisados em mudas de Acacia mangium Willd. Sugere-se usar na formulação do substrato alternativo $25 \%$ de CAC $+75 \%$ de substrato comercial Bioflora ${ }^{\circledR}$, considerando que este tratamento foi o que apresentou melhor resultado no crescimento inicial de mudas de Acacia mangium Willd.

Palavras-chave: Acacia australiana, substrato alternativo, espécies florestais.

\section{ABSTRACT}

The objective of this study was to evaluate the influence of carbonized rice husk on initial growth of Acacia mangium Willd seedlings. The experiment was carried out in the forest of the Federal University of Tocantins, Campus of Gurupi-TO, conducted in a completely randomized design, with five treatments T1: 0\% Carbonized Rice Peel $(C A C)+100 \%$ Bioflora ${ }^{\circledR}$ Commercial Substrate, T2 : 25\% CCS + 75\% Commercial substrate; T3: 50\% CAC + 50\% Commercial substrate; T4: 75\% CAC + 25\% Commercial substrate; T5: 100\% CAC + 0\% Commercial substrate, with 4 replicates, each replicate with 18 seeds. The percentage of emergence (\% E), shoot height $(H)$, shoot diameter (DC), shoot dry matter weight (PMSPA), root dry weight (PMSR) and dry matter weight Total (PMST). The results indicated that the use of carbonized rice husk added in different proportions to commercial Bioflora ${ }^{\circledR}$ substrate presented significant results in the parameters analyzed in Acacia mangium Willd seedlings. It is suggested that $25 \%$ CAC $+75 \%$ of Bioflora ${ }^{\circledR}$ commercial substrate is used in the alternative 
substrate formulation, considering that this treatment was the one that presented the best result in initial growth of Acacia mangium Willd seedlings.

Keywords: Acacia australiana, alternative substrate, forest species.

\section{RESUMEN}

Este estudio tuvo como objetivo evaluar la influencia de cáscara de arroz carbonizado en el crecimiento inicial de las plántulas de Acacia mangium Willd. El experimento se llevó a cabo en el vivero forestal de la Universidad Federal de Tocantins, el campus Gurupí-TO, llevada a cabo en un diseño completamente al azar con cinco

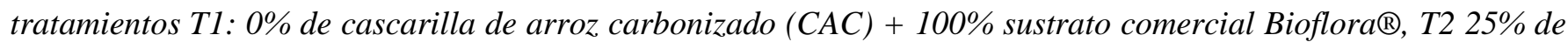
CCS $+75 \%$ de sustrato comercial; T3: $50 \%$ del sustrato comercial CAC $+50 \% ;$ T4: $75 \%$ CCS + 25\% sustrato comercial; T5: 100\% + 0\% CCS sustrato comercial con 4 repeticiones, cada repetición de 18 semillas. porcentaje de emergencia se analizó (\% E), disparar la altura $(H)$, el diámetro del tallo $(D C)$, el peso de materia seca de la parte aérea (PMSPA) Peso de las raíces secas (PMSR) y el peso seco total (PMST). Los resultados indicaron que el uso de cáscara de arroz carbonizado añadió en diferentes proporciones con el sustrato comercial Bioflora® mostró resultados significativos en los parámetros analizados Acacia mangium plántulas Willd. Se sugiere utilizar en la formulación de CAC sustrato alternativo $25 \%+75 \%$ sustrato comercial Bioflora ${ }^{\circledR}$, mientras que este tratamiento mostró el mejor resultado en el crecimiento inicial de Acacia mangium plantas de semillero Willd.

Descriptores: Acacia australiana, sustrato alternativo, especies forestales.

\section{INTRODUÇÃO}

O gênero Acacia ainda é pouco cultivado no Brasil, no ano de 2014 o país alcançou 7,74 milhões de hectares com florestas plantadas, com o gênero Acacia correspondendo apenas por cerca de 2\% dessa área. (IBA, 2016; SEPLAN, 2015).

Acacia mangium Willd. pertence a família Fabaceae, subfamília Mimosoideae, cujo o gênero compreende aproximadamente 700 a 800 espécies, ocorrendo naturalmente em regiões tropicais $\mathrm{e}$ subtropicais (GONÇALVES e LELIS, 2012). Nativa da parte noroeste da Austrália, de Papua Nova-Guiné e do oeste da Indonésia, é uma espécie pioneira e muito cultivada em todo o mundo, especialmente para energia primária e celulose além de usos variados, para a construção civil e produção de móveis (IPEF, 2016).

Acacia mangium Willd. destaca-se pela rusticidade e adaptabilidade às condições edafoclimáticas adversas, pelo rápido crescimento, elevada produção de biomassa e capacidade de formar simbioses com microrganismos do solo. Além disso, é adaptável para uma ampla gama de solos ácidos, $\mathrm{pH} 4,5-6,5$, inclusive tolerando solos de baixa fertilidade ou com pouca drenagem, possui potencial de uso em programas de reflorestamento e recuperação de áreas degradadas (CALDEIRA et al., 2014).

A formação de mudas florestais de qualidade está relacionada com o manejo, condução das mudas no viveiro e com os substratos utilizados, pois a germinação de sementes, formação do sistema radicular e parte aérea estão associadas com a aeração, drenagem, retenção de água e disponibilidade balanceada de nutrientes que são particularidades de cada substrato (CALDEIRA et al., 2014).

O substrato exerce influência significativa no desenvolvimento das mudas, e vários são os materiais que podem ser utilizados na sua composição (Santos et al., 2013). A casca de arroz carbonizada têm baixa densidade e peso específico, além de lenta biodegradação, permanecendo em sua forma original por longo período de tempo, apresenta alta capacidade de drenagem, fácil manuseio, boa aeração, alta porosidade, peso reduzido, forma 
floculada sendo livre de patógenos e nematoides (FAVALESSA, 2011).

Tais propriedades, associadas ao baixo custo material, sugere a necessidade de avaliar a casca de arroz carbonizada como componente de substrato alternativo.

Diante do exposto, objetivou-se avaliar a influência do uso da casca de arroz carbonizada no crescimento inicial de mudas de Acacia mangium Willd.

\section{MATERIAL E MÉTODOS}

O trabalho foi conduzido no viveiro florestal da Universidade Federal do Tocantins (UFT), Campus de Gurupi - TO no período de outubro a dezembro de 2016, localizado na região sul do Estado do Tocantins, a $280 \mathrm{~m}$ de altitude, sob as coordenadas $11^{\circ} 43^{\prime} 45^{\prime \prime}$ de latitude e $49^{\circ} 04^{\prime} 07^{\prime \prime}$ de longitude.

O clima predominante da região segundo Thornthwaite é do tipo C2wA "a", sendo caracterizado por um clima úmido subúmido com moderada deficiência hídrica no inverno e as precipitações pluviométricas entre 1.300 a $1.700 \mathrm{~mm}$ e temperatura média anual de $26^{\circ} \mathrm{C}$ (SEPLAN, 2012).

As sementes de Acacia mangium Willd. foram adquiridas no Laboratório de Sementes Florestais da Universidade Federal do Tocantins, campus de Gurupi, as mesmas foram selecionadas manualmente, descartando-se as que apresentavam injurias ou deformadas.

$\mathrm{O}$ experimento avaliou cinco tratamentos, os quais consistiram na adição de casca de arroz carbonizada ao substrato comercial Bioflora ${ }^{\circledR}$ nas seguintes proporções: T1: 0\% de Casca de Arroz Carbonizada $(\mathrm{CAC})+100 \%$ de Substrato comercial; T2: $25 \%$ de CAC $+75 \%$ de Substrato comercial, T3: $50 \%$ de CAC $+50 \%$ de Substrato comercial, T4:
$75 \%$ de CAC $+25 \%$ de Substrato comercial, T5: $100 \%$ de CAC $+0 \%$ de Substrato comercial Bioflora ${ }^{\circledR}$.

Devido as sementes de Acacia mangium Willd. apresentarem dormência tegumentar, as mesmas foram imersas em água fervente por 36 segundos para superação da dormência. Posteriormente foram semeadas a $1 \mathrm{~cm}$ de profundidade em copos descartáveis com capacidade volumétrica de $200 \mathrm{~cm}^{3}$, com quatro perfurações no fundo para facilitar à drenagem de água.

Após a semeadura realizou-se duas irrigações diárias a fim de manter o controle da umidade desejável para emergência. Os indivíduos emergidos foram contabilizados seguindo o método proposto pelo Manual de Regras para Análise de Sementes - RAS (BRASIL, 2009).

Foram analisadas as características: porcentagem de emergência (\% E), altura da parte aérea $(\mathrm{H})$, diâmetro do coleto $(\mathrm{DC})$, peso de matéria seca da parte aérea (PMSPA), peso de matéria seca das raízes (PMSR), e peso de matéria seca total (PMST).

A altura da parte aérea foi determinada aos 15, 30 e 45 dias após a semeadura (DAS) por meio da utilização de régua $(\mathrm{cm})$ a partir do nível do substrato até o ápice da última folha. $\mathrm{O}$ diâmetro do coleto também foi aferido aos 15, 30 e 45 DAS com paquímetro digital (mm) ao nível do substrato.

A avaliação de emergência das plântulas foi realizada aos 15 dias após a semeadura, por meio de quantificação do número de plântulas emergidas em cada recipiente.

As determinações dos pesos de matéria seca da parte aérea (PMSPA) e peso de matéria seca das raízes (PMSR) foram obtidos por meio de balança de precisão a partir do material seco em estufa, regulada para $72^{\circ} \mathrm{C}$, por 72 horas. O peso de matéria seca total 
(PMST) obteve-se pela soma dos pesos acima citados.

O delineamento experimental utilizado foi o inteiramente casualizado (DIC), com cinco tratamentos e quatro repetições. Cada repetição 18 sementes, totalizando 72 para cada tratamento. As médias dos tratamentos foram conferidas através do Software Assistat 7.7 pelo teste Scott e Knott ao nível de $5 \%$ de probabilidade.

\section{RESULTADOS E DISCUSSÃO}

As características avaliadas: altura $(\mathrm{H})$, diâmetro do coleto (DC), porcentagem de emergência (\% E), apresentaram respostas distintas entre si, porém os resultados para peso da matéria seca da parte aérea (PMSPA), peso da matéria seca da raíz (PMSR) e peso da matéria seca total (PMST) não se diferiram estatisticamente ao nível de $5 \%$ de probabilidade pelo teste Scott e Knott.

Em relação a porcentagem de emergência verificou-se que os tratamentos T1; T2; T3 e T5, não apresentaram diferenças significativas entre si, atingindo índices acima de $98 \%$ de emergência, apenas o T4 se diferiu dos demais negativamente (Tabela 1), sendo portanto inferior neste parâmetro.

Tabela 1. Valores médios da porcentagem de emergência de mudas de Acacia mangiun Willd. avaliados aos 15 DAS.

\begin{tabular}{cc}
\hline Tratamentos & \% E \\
\hline T1 & $100 \mathrm{a}$ \\
T2 & $98 \mathrm{a}$ \\
T3 & $100 \mathrm{a}$ \\
T4 & $93 \mathrm{~b}$ \\
T5 & $100 \mathrm{a}$ \\
\hline
\end{tabular}

$\% \mathbf{E}=$ Porcentagem de Emergência. Médias seguidas pela mesma letra não diferem entre si pelo teste Scott e Knott ao nível de 5\% de probabilidade.

Souza et al., (2015) avaliando o efeito de diferentes substratos na produção e qualidade de mudas de Eugenia involucrata DC verificaram que o tratamento que continha casca de arroz carbonizada $\left(50 \%\right.$ substrato comercial Plantmax ${ }^{\circledR}+50 \%$ substrato casca de arroz carbonizada), propiciou o melhor resultado no percentual germinativo, atingindo $93 \%$.

Já as médias de altura das plântulas de Acacia mangiun Willd. diferiram significativamente entre os tratamentos testados (Tabela 2).

Tabela 2. Valores médios de altura (H) e diâmetro do coleto (D) avaliados aos 15, 30 e 45 DAS de mudas de Acacia mangiun Willd.

\begin{tabular}{|c|c|c|c|c|c|c|}
\hline \multirow{2}{*}{ Tratamentos } & \multicolumn{2}{|c|}{15 DAS } & \multicolumn{2}{|c|}{30 DAS } & \multicolumn{2}{|c|}{45 DAS } \\
\hline & H (cm) & DC (mm) & H (cm) & DC (mm) & H (cm) & DC (mm) \\
\hline T1 & $1,05 \mathrm{~b}$ & $0,65 \mathrm{a}$ & $1,50 \mathrm{~b}$ & $0,75 \mathrm{a}$ & $1,58 \mathrm{~b}$ & $0,80 \mathrm{a}$ \\
\hline $\mathbf{T 2}$ & $1,28 \mathrm{a}$ & $0,67 \mathrm{a}$ & $1,83 \mathrm{a}$ & $0,74 \mathrm{a}$ & $2,00 \mathrm{a}$ & $0,82 \mathrm{a}$ \\
\hline T3 & $1,14 \mathrm{a}$ & $0,66 \mathrm{a}$ & $1,72 \mathrm{a}$ & $0,72 \mathrm{a}$ & $1,85 \mathrm{a}$ & $0,77 \mathrm{~b}$ \\
\hline T4 & $1,02 \mathrm{~b}$ & $0,64 \mathrm{a}$ & $1,52 \mathrm{~b}$ & $0,72 \mathrm{a}$ & $1,59 \mathrm{~b}$ & $0,77 \mathrm{~b}$ \\
\hline T5 & $1,20 \mathrm{a}$ & $0,64 \mathrm{a}$ & $1,87 \mathrm{a}$ & $0,71 \mathrm{a}$ & $2,20 \mathrm{a}$ & $0,78 \mathrm{~b}$ \\
\hline $\mathrm{CV}(\%)$ & 6,42 & 3,01 & 7,70 & 3,66 & 9,98 & 2,49 \\
\hline
\end{tabular}

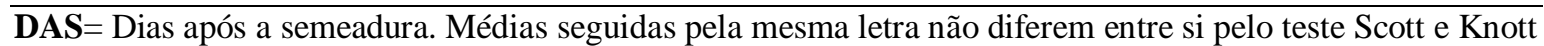
ao nível de $5 \%$ de probabilidade.

Eloy et al. (2013) citam que a altura da parte aérea por ser uma variável de fácil medição e não ser um método destrutivo é utilizada com eficiência para estimar o padrão da qualidade de mudas em viveiros. Fornece uma excelente estimativa da predição do crescimento inicial no campo, sendo tecnicamente aceita como boa medida 
do potencial de desempenho das mudas (CALDEIRA et al, 2014).

Os resultados obtidos aos 15, 30 e 45 dias após a semeadura (DAS) mostraram que os tratamentos T2; $\mathbf{T 3}$ e $\mathbf{T 5}$, os quais apresentavam em sua composição adição de CAC em 25\%, 50\% e 100\%, respectivamente, são estatisticamente semelhantes entre si, porém preponderantes aos demais em relação ao crescimento de mudas em altura.

Dados estes que corroboram com Kratz e Wendling (2013), onde os mesmos estudando substratos renováveis em mudas de Eucalyptus dunnii Maiden, destacaram que substratos formados com $50 \%$ de casca de arroz carbonizada $+50 \%$ de vermiculita fina apresentaram resultados positivos (maior crescimento das mudas) além de ressaltarem que a densidade aparente, porosidade total, macroporosidade, $\mathrm{pH}$ e a capacidade de troca catiônica apresentaram correlação com o crescimento das mudas.

Em relação ao diâmetro do coleto observou-se que as mudas de Acacia mangiun Willd. avaliadas aos 15 e 30 dias após a semeadura não diferiram estatisticamente entre si em nenhum dos tratamentos testados, no entanto, aos 45 (DAS) os tratamentos T1 e T2 destacaram-se, sendo estatisticamente superiores aos demais tratamentos avaliados (Tabela 2).

Em consonância com os dados do peso da matéria seca da parte aérea, peso da matéria seca da raiz e peso da matéria seca total (Tabela 3), estatisticamente pelo teste Scott e Knott ao nível de $5 \%$ de probabilidade, não se constataram diferenças significativas entre os tratamentos avaliados.

Tabela 3. Valores médios de Peso da Massa Seca da Parte Aérea (PMSPA), Peso da Massa Seca da Raiz (PMSR) e Peso da Massa Seca Total (PMST) de mudas de Acacia mangiun Willd.

\begin{tabular}{cccc}
\hline Tratamentos & PMSPA $(\mathbf{g})$ & PMSR $(\mathbf{g})$ & PMST $(\mathbf{g})$ \\
\hline T1 & $0,037 \mathrm{a}$ & $0,031 \mathrm{a}$ & $0,069 \mathrm{a}$ \\
T2 & $0,024 \mathrm{a}$ & $0,020 \mathrm{a}$ & $0,044 \mathrm{a}$ \\
T3 & $0,028 \mathrm{a}$ & $0,021 \mathrm{a}$ & $0,050 \mathrm{a}$ \\
T4 & $0,033 \mathrm{a}$ & $0,028 \mathrm{a}$ & $0,061 \mathrm{a}$ \\
T5 & $0,021 \mathrm{a}$ & $0,035 \mathrm{a}$ & $0,057 \mathrm{a}$ \\
\hline CV $(\%)$ & 27,20 & 46,50 & 30,08
\end{tabular}

Médias seguidas pela mesma letra não diferem entre si pelo teste Scott e Knott ao nível de 5\% de probabilidade.

Caldeira et al. (2014) citam que a massa seca da parte aérea, deve sempre ser considerada como característica de qualidade das mudas, apesar de ser um método destrutivo, visto que indica a rusticidade de uma muda, pois está relacionada com um melhor vigor e capacidade fotossintética, ou seja, quanto maior a sua média mais rustificada será a muda.

No presente estudo constatou-se que a proporção de $25 \%$ de CAC $+75 \%$ de substrato comercial Bioflora ${ }^{\circledR}$ foi o melhor tratamento testado, fato que pode ser explicado pelas características da espécie, pois Acacia mangium Willd. apresenta boa adaptabilidade a condições edafoclimáticas adversas, é uma espécie rústica de rápido crescimento e tolerante a solos de baixa fertilidade.

\section{CONCLUSÃO}

No que diz respeito a emergência de plântulas de Acacia mangium Willd., com exceção do T4, conclui-se que todos os tratamentos proporcionaram resultados satisfatórios na 
porcentagem de emergência, sendo, portanto, recomendáveis para esta finalidade.

Para se obter um bom crescimento inicial de mudas da espécie objeto deste estudo, sugere-se usar na formulação do substrato alternativo $25 \%$ de $\mathrm{CAC}+75 \%$ de substrato comercial Bioflora ${ }^{\circledR}$.

Todos os autores declararam não haver qualquer potencial conflito de interesses referente a este artigo.

\section{REFERÊNCIAS}

BRASIL. Ministério da Agricultura, Pecuária e Abastecimento. Regras para análise de sementes. Brasília, DF: MAPA, 2009. p.148-223, 2009.

CALDEIRA, M. V. W.; FAVALESSA, M.; GONÇALVES, E. O.; DELARMELINA, W. M.; SANTOS, F. E. V.; VIERA, M. Lodo de esgoto como componente de substrato para produção de mudas de Acacia mangium Wild. Com. Sci., Bom Jesus, v.5, n.1, p.34-43, Jan./Mar. 2014.

ELOY, E.; CARON, B. O.; SCHMIDT, D.; BEHLING, A.; SCHWERS, L.; ELLI, E. F. Avaliação da qualidade de mudas de Eucalyptus grandis utilizando parâmetros morfológicos. Floresta, Curitiba, PR, v. 43, n. 3, p. 373 - 384, jul. / set. 2013.

FAVALESSA, M. Substratos renováveis e não renováveis na produção de mudas de Acácia mangium. 2011. 60f. (Engenharia Florestal) Universidade Federal do Espirito Santo, Jerônimo Monteiro, 2011.
GONÇALVES, F. G.; LELIS, R. C. C. Caracterização Tecnológica da Madeira de Acácia mangium Willd em Plantio Consorciado com Eucalipto. Floresta e Ambiente 2012; 19(3):286295.

IBIA - Indústria Brasileira de Árvores. Relatório 2015. Disponível em: <http://iba.org/images/shared/iba_2016.pdf>. Acesso em novembro de 2016.

IPEF - Instituto de Pesquisas e Estudos Florestais. Disponível em: <http://www.ipef.br/identificacao/acacia.mangium.as p>. Acesso em novembro de 2016.

KRATZ, D.; WENDLING, I. Produção de mudas de Eucalyptus dunnii em substratos renováveis. Floresta 43: 125-136. 2013.

SANTOS, F. E. V.; CALDEIRA, M. V. W.; KUNZ, S. H. Qualidade de mudas de Parapiptadenia rigida (Benth.) Brenan produzidas em diferentes substratos com lodo de esgoto e casca de arroz. Ecologia e Nutrição Florestal, Santa Maria-RS, v.1, n.2, p.5562, mai./ago., 2013.

SEPLAN - Secretaria do Planejamento e Orçamento. Visão estratégica do agronegócio no Tocantins. SEPLAN, Palmas, 73 p. 2015.

SEPLAN - Secretaria do Planejamento e Orçamento. Visão estratégica do agronegócio no Tocantins. SEPLAN, Palmas, 2012.

SOUZA, P. L. T.; VIEIRA, L. R.; BOLIGON, A. A.; VESTENA, S. Produção e qualidade de mudas de Eugenia involucrata DC. em diferentes substratos. Revista Biociências - Universidade de Taubaté V.21 no $1-2015$. 